\title{
Analisis Pendapatan Usahatani Sawi di Kawasan Ekonomi Masyarakat Desa Bannae Kecamatan Insana Barat
}

\author{
Alfridus Hane $e^{\mathrm{a}}$, dan Simon Juan Kune ${ }^{\mathrm{b}}$ \\ ${ }^{a}$ Fakultas Pertanian, Universitas Timor, Kefamenanu, TTU - NTT, Indonesia. \\ ${ }^{b}$ Fakultas Pertanian, Universitas Timor, Kefamenanu, TTU - NTT, Indonesia.
}

\section{Article Info}

Article history:

Received 8 Desember 2017

Received in revised form 5 Maret 2018

Accepted 23 Maret 2018

\section{Keywords:}

Pendapatan

Usahatani

Sawi

Bannae

\section{Abstrak}

Desa Bannae merupakan desa yang memiliki banyak sumber daya yang dapat dimanfaatkan dan dikembangkan untuk peningkatan kesejahteraan masyarakatnya. Tujuan penelitian ini adalah untuk mengetahui 1) gambaran usahatani sawi; dan 2) pendapatan usahatan sawi di Kawasan Ekonomi Masyarakat desa Bannae, kecamatan Insana Barat, kabupaten TTU. Penelitian dilaksanakan di desa Bannae, kecamatan Insana Barat, Kabupaten TTU, pada bulan April sampai Juli 2017. Populasi dalam penelitian ini adalah semua petani sawi di desa Bannae yang mengusahakan sawi sehingga populasi dalam penelitian berjumlah 51 orang, teknik pengambilan sampel dalam penelitian ini menggunakan teknik sensus sehingga semua populasi menjadi sampel yakni sebanyak 51 orang. Data yang diperoleh dikumpulkan kemudian ditabulasi dan dianalisis berdasarkan tujuan penelitian. Untuk mengetahui gambaran umum produksi sawi maka digunakan metode analisis deskriptif kualitatif, sedangkan mengetahui pendapatan usahatani sawi maka dilakukan analisis pendapatan. Hasil penelitian menunjukkan usahatani sawi di desa Bannae dimulai dari pengolahan lahan dilakukan oleh tenaga kerja pria dan wanita, tanah diolah menggunakan alat-alat meliputi pacul, linggis, parang, dan tajak, kemudian dilanjutkan dengan persiapan benih. Penanaman dilakukan setelah bibit sayur sawi mempunyai 4 sampai 5 helai daun. Sebelum penanaman bedengan disiram terlebih dahulu. Petan membuat lubang tanam pada bedengan jarak $+20 \times 20 \mathrm{~cm}$. Bibit sayur sawi ditanam 2-3 bibit per lubang. Setelah tanam bedengan disiram dengan air secukupnya. Selanjutnya dilakukan pemeliharaan hingga panen dan pasca panen. Rata-rata biaya yang dikeluarkan petani dalam berusahatani sawi sebesar Rp697.470,59 dari total keseluruhan biaya yang dikeluarkan sebesar Rp35.571.000,00. Total penerimaan sebesar Rp42.749.000,00 dengan rata-rata sebesar Rp838.215,69. Total pendapatan petani sayur sawi sebesar Rp7.178.000,00 dengan rata-rata pendapatan sebesar Rp140.745,10 per musim tanam. (02018 dipublikasikan oleh Agrimor.

\section{Pendahuluan}

Desa Bannae adalah salah satu desa di kecamatan Insana Barat, kabupaten Timor Tengah Utara (TTU) dan merupakan desa yang memiliki banyak sumber daya yang dapat dimanfaatkan dan dikembangkan untuk peningkatan kesejahteraan masyarakatnya. Hal ini kemudian dilirik oleh salah satu BUMN yakni Pertamina untuk membantu masyarakat mengelolanya guna meningkatkan kesejahteraan masyarakat melalui pembentukan sebuah Kawasan Ekonomi Masyarakat (KEM). Hal ini sejalan dengan yang menyatakan bahwa Taena, (2009) pemanfaatan sumberdaya perlu diarahkan pada suatu model pengembangan ekonomi wilayah yang tepat agar dapat memaksimalkan kesejahteraan masyarakat.

Lahan yang digunakan sebagai Kawasan Ekonomi Masyarakat seluas 4 ha yang di dalamnya telah disediakan sebuah waduk sebagai tempat penampung air. KEM desa Bannae dikelola oleh 51 orang anggota, di dalam kawasan tersebut sebagian digunakan untuk bercocok tanam hortikultura, salah satunya adalah sayur sawi. KEM desa Bannae bertempat di lokasi yang strategis karena tidak begitu jauh dari Kefamenanu sebagai ibu kota kabupaten sehingga sayuran yang diproduksi dari wilayah ini mudah untuk dipasarkan. Selain itu, Pay \& Nubatonis, (2017) telah memberikan gambaran bahwa produksi sayuran dari wilayah kabupaten TTU dapat dipasarkan hingga ke Kupang sebagai ibu kota provinsi.

Manfaat sayur sawi yang sangat besar sehingga banyak yang dibutuhkan oleh masyarakat. Ini merupakan peluang usaha bagi petani sebagai sumber pendapatan dengan berusaha meningkatkan produksinya seoptimal mungkin. Ha yang perlu mendapat perhatian petani adalah dasar usahatani, di antaranya pengolahan tanah, pemupukan, pengelolaan air, persemaian benih, penanaman, pemeliharaan tanaman, pemungutan hasil, penanganan hasil juga perlu pemahaman analisis usaha bila tujuan bertanam untuk dijual (Sunarjono, 2002) Selanjutnya menurut Redaksi Health Secret, (2015) sawi mengandung vitamin A dalam jumlah sangat tinggi, juga mengandung vitamin C, vitamin B (niasin, tiamin dan riboflavin), zat bezi, kalsium, fosfor, dan kalium. Dalam 100 gram sawi memberikan 22 kalori, sehingga sawi merupakan sayuran yang bagus untuk diet rendah kalori. Kandungan seratnya yang tinggi juga bermanfaat sebagai pencegah konstipasi (sembelit) dan memperlancar pencernaan. Secara empiris, sawi juga digunakan sebagai obat rematik dan skitika.

Menurut Haryanto, (2007) agar suatu usahatani tidak rugi maka harus diketahui terlebih dahulu analisis usahataninya. Suratiyah, (2006) juga menyatakan bahwa dengan memahami data-data usahatani maka petani dapat merencanakan produksi sesuai dengan pendapatan yang diinginkan. Oleh karena itu, untuk mendukung pengembangan KEM desa Bannae maka perlu dilakukan kajian dengan topik "Analisis Pendapatan Usahatani Sawi di Kawasan Ekonomi Masyarakat Desa Bannae Kecamatan Insana Barat”. Tujuan penelitian ini adalah untuk mengetahui 1) gambaran usahatani sawi; dan 2) pendapatan usahatani sawi di Kawasan Ekonomi Masyarakat desa Bannae, kecamatan Insana Barat, kabupaten TTU.

\section{Metode}

Penelitian dilaksanakan di desa Bannae, kecamatan Insana Barat, Kabupaten TTU, pada bulan April sampai Juli 2017. Populasi dalam penelitian ini adalah semua petani sawi di desa Bannae, kecamatan Insana Barat yang mengusahakan sawi sehingga populasi dalam penelitian berjumlah 51 orang. Teknik pengambilan sampel dalam penelitian ini menggunakan teknik sensus sesuai petunjuk Ating \& Sambas, (2006) sehingga semua populasi menjadi sampel sehingga jumlah sampel yang digunakan adalah sebanyak 51 orang.

Data yang digunakan dalam penelitian ini adalah data primer yang diperoleh dengan teknik wawancara langsung dengan responden atau petani pengusaha sawi di lokasi penelitian berdasarkan daftar pertanyaan yang disiapkan oleh peneliti sedangkan data sekunder diperoleh dari instansi atau lembaga terkait.

Data yang diperoleh dikumpulkan kemudian ditabulasi dan dianalisis berdasarkan tujuan penelitian. Untuk mengetahui gambaran umum produksi sawi maka digunakan metode analisis deskriptif kualitatif sesuai petunjuk Sugiyono, (2006), sedangkan mengetahui pendapatan usahatani sawi maka dilakukan analisis pendapatan sesuai petunjuk Soekartawi, (1995), dengan formula:

$$
\begin{aligned}
& \mathrm{Pd}=\mathrm{TR}-\mathrm{TC} \\
& \mathrm{TR}=\mathrm{Py} . \mathrm{Y}
\end{aligned}
$$

$\mathrm{TC}=\mathrm{FRC}+\mathrm{VC}$

Sehingga Pd $=\{[\mathrm{Py} . \mathrm{Y}] /[\mathrm{FC}+\mathrm{VC}]\}$ dimana:

$\mathrm{Pd}=$ Pendapatan usahatani sawi

Py = Harga sayur sawi

$\mathrm{Y}=$ Produksi yang diperoleh

$\mathrm{FC}=$ Biaya tetap

$\mathrm{VC}=$ Biaya variabel

Biaya produksi yang dikeluarkan oleh petani dihitung sesuai petunjuk Hadisapoetro, (1973).

\section{Hasil dan Pembahasan}

\subsection{Gambaran Usahatani Sawi}

Kelompok tani KEM desa Bannae memilih komoditi sayur sawi karena tanaman sayur sawi memiliki umur panen yang cepat, dan tumbuh dengan baik pada musim kemarau, sehingga dapat di tanam sepanjang tahun. Selain itu juga lokasi penelitian memiliki satu embung sehingga memudahkan petani dalam penyiraman. Tahap-tahap usahatani sawi antara lain persiapan dan pengolahan lahan, pemupukan dasar, persemaian, penanaman, penyulaman, pemeliharaan, pengendalian hama, pemupukan, panen dan pasca panen.

a. Pengolahan Lahan

Pengolahan lahan dimulai dengan tanah dibalik terlebih dahulu menggunakan linggis dan membuat bedeng berukuran lebar $+2-3$ meter dengan panjang bedengan disesuaikan dengan ukuran lahan yang dimiliki sedangkan tinggi bedengan mencapai $+20-30 \mathrm{~cm}$.

\section{b. Benih}

Benih yang digunakan di Desa Bannae dalam berusahatani sayur sawi adalah benih sayur sawi yang dibeli di toko pertanian. Masyarakat memilih benih merek Bangkok LP Cap Panah Merah karena selain memiliki harga yang murah, benih tersebut juga memiliki kualitas yang sangat bagus.

\section{c. Penanaman}

Penanaman dilakukan setelah bibit sayur sawi mempunyai 4-5 helai daun. Sebelum penanaman bedengan disiram terlebih dahulu. Petani membuat lubang tanam pada bedengan jarak $+20 \times 20 \mathrm{~cm}$. Sebelum bibit dicabut, disiram terlebih dahulu agar akar bibit tidak rusak. Bibit sayur sawi ditanam $+2-3$ bibit per lubang, sesudah tanam bedengan tersebut disiram dengan air secukupnya.

\section{d. Penyulaman}

Penyulaman dilakukan oleh masyarakat petani sayur sawi apabila bibit yang tanam tidak tumbuh atau tanaman terserang hama dan penyakit. Penyulaman biasanya dilakukan pada saat tanaman masih berumur +1 minggu sehingga waktu panen dapat bersamaan dengan tanaman lain tidak terserang hama dan penyakit. 
e. Pemeliharaan

- Penyiraman

Penyiraman dilakukan dua kali dalam sehari yaitu pada pagi dan sore hari, untuk lebih memudahkan saat penyiraman petani menggunakan motor air karena keadaan bedengan yang luas.

- Pemupukan

Kegiatan pemupukan dilakukan dengan dua tahap yaitu pemupukan dasar dan pemupukan lanjutan. Pemupukan dasar dilakukan setelah bedengan dibuat dengan cara bedengan didiamkan +3-4 hari agar tanah kering dan dilakukan pemupukan dasar, dilakukan dengan cara menghamburkan dedaunan seperti daun gamal di atas bedengan atau kotoran sapi, kuda, dan kambing, dan kelelawar yang sudah kering di atas bedengan secara merata dan dilakukan penyiraman dengan tujuan agar pupuk kandang yang telah ditaburkan menyatu dengan tanah.

- Pengendalian Hama dan Penyakit

Hama yang sering menyerang tanaman sayur sawi antara lain ulat grayak, kutu daun. Sedangkan penyakit antara lain karat putih. Untuk mencegah hama dan penyakit tersebut petani menggunakan pestisida Green Tonik. Petani memilih pestisida ini karena tidak menimbulkan risiko terhadap tanaman sayur sawi dan reaksinya sangat cepat dalam mengatasi hama atau penyakit yang menyerang tanaman sayur sawi tersebut.

- Gulma

Pengendalian gulma dilakukan secara manual menggunakan tofa atau mencabut semua tanaman lain yang tumbuh di atas bedengan. Pembersihan gulma dan dilakukan secara hati-hati sehingga tidak menginjak tanaman sayur sawi tersebut.

\section{f. Panen}

Petani melakukan pemanenan setelah tanaman sayur sawi berumur 40-50 hari, panen dilakukan dengan cara mencabut sayur sawi dari bedengan dan membersihkan sisa tanah yang masih melekat pada sayur sawi dengan cara dipotong pada pangkal batang yang dekat dengan akar. Petani melakukan pada saat pagi hari dengan tujuan dijual kepada pedagang pengumpul atau dijual sendiri.

\section{g. Pasca Panen}

Pasca panen adalah tahap terakhir dalam kegiatan usahatani, pasca panen bertujuan untuk menjaga kesegaran sayur sawi tersebut dengan cara lakukan percikan air bersih pada bagian daun dan disimpan di tempat yang teduh dan membungkus sayur sawi tersebut menggunakan daun pisang. Sayur sawi tersebut diikat menggunakan tali gewang.

\subsection{Analisis Pendapatan Usahatani Sawi}

Lahan yang digunakan untuk berusahatani sayur sawi adalah milik sendiri dengan luas berkisar antara 10-21 are dengan perincian 25 orang petani atau $49 \%$ memiliki lahan dengan luas 10-12 are, 20 orang petani atau 39\% memiliki lahan dengan luas 13-17 are, dan hanya 12 orang petani atau $12 \%$ yang memiliki lahan dengan luas 18-21 are.

Tenaga kerja yang digunakan berasal dari tenaga kerja dalam keluarga yang merupakan sumbangan tenaga kerja dalam memproduksi sayur sawi sehingga untuk biaya tenaga kerja dalam penelitian ini tidak di hitung dengan uang namun peneliti hanya menghitung biaya konsumsi selama berusahatani sayur sawi. Rata-rata curahan tenaga kerja dalam usahatani dapat dilihat pada Gambar 1.

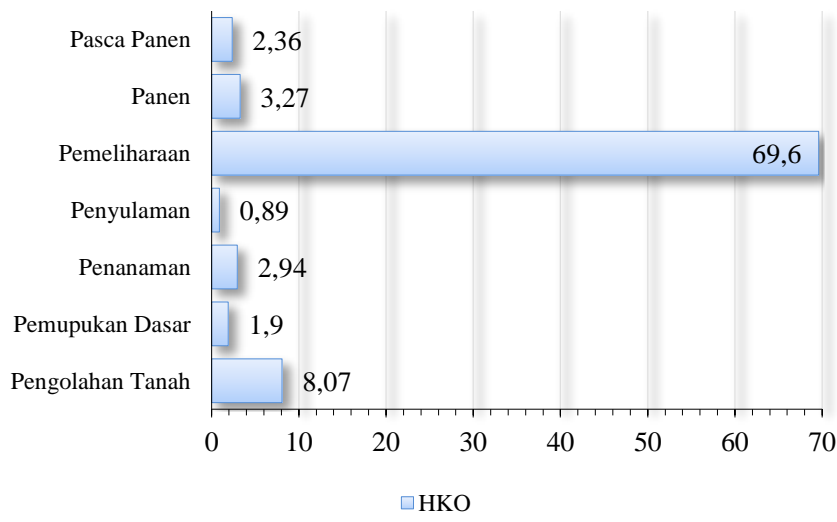

Gambar 1. Rata-Rata Curahan Tenaga Kerja

\section{a. Biaya Produksi Usahatani Sawi}

Total biaya produksi sawi di KEM desa Bannae sebesar Rp35.571.000,00 dengan rata-rata biaya produksi sebesar Rp697.470,59. Biaya produksi ini terdiri dari biaya variabel dan biaya tetap.

\section{- Biaya Variabel}

Biaya variabel merupakan korbanan yang harus dikeluarkan terus menerus oleh petani untuk satu kali produksi. Berdasarkan hasil penelitian yang dilakukan di petani Kawasan Ekonomi Masyarakat (KEM) Desa Bannae total biaya yang di keluarkan dalam satu kali usahatani sayur sawi sebesar Rp13.851.000,00 dengan rata-rata biaya yang dikeluarkan dalam satu kali produksi untuk usahatani sayur sawi sebesar Rp271.588,24.

\section{Tabel 1. Biaya Variabel Usahatani Sawi di KEM Desa Bannae}

\begin{tabular}{|c|c|c|c|}
\hline No & Jenis Biaya & Total Biaya (Rp) & $\begin{array}{c}\text { Rata-Rata Biaya } \\
\text { (RP) }\end{array}$ \\
\hline 1 & Benih & 1.460 .000 & $28.627,45$ \\
\hline 2 & Pupuk & 2.079 .000 & $40.764,71$ \\
\hline 3 & Transportasi Penjualan & 347.000 & $6.803,92$ \\
\hline 4 & Pestisida & 5.970 .000 & $117.058,82$ \\
\hline 5 & Transportasi Pembelian Saprodi & 720.000 & $14.117,65$ \\
\hline 6 & Bensin & 1.480 .000 & $29.019,61$ \\
\hline \multirow[t]{2}{*}{7} & Biaya Konsumsi & 1.795 .000 & $35,197,08$ \\
\hline & Jumlah & 13.851 .000 & $271.588,24$ \\
\hline
\end{tabular}

- Biaya Tetap

Biaya penyusutan alat yaitu alat-alat yang digunakan hanya untuk usahatani sayur sawi. Alat-alat yang digunakan pada usahatani sayur sawi tidak digunakan pada usahatani lainnya karena khusus pada usahatani itu sendiri. Biaya penyusutan alat meliputi alat berupa selang, linggis, motor air, parang, ember, dan pisau. Total biaya penyusutan alat sebesar Rp21.720.000,00 dengan rata-rata biaya penyusutan sebesar Rp425.882,35

\section{b. Penerimaan Usahatani Sawi}

Penerimaan merupakan perkalian antara produksi sayur sawi (ikat) yang diperoleh dengan harga jual sayur sawi (per ikat) di tingkat masyarakat. Total produksi sawi di KEM desa Bannae bentuk ikat yakni sebanyak 42.749 ikat per musim tanam, sedangkan produksi dari setiap petani bervariasi bergantung pada faktor sosial ekonomi dari setiap petani. Menurut Usboko \& Fallo, (2016) luas lahan, bibit, pupuk kandang, dan jumlah tanggungan keluarga berpengaruh pada produksi sawi.

Harga sayur sawi di tingkat masyarakat sebesar Rp1.000,00 per ikat. Dengan demikian total penerimaan usahatani sebesar Rp42.749.000,00 dengan rata-rata penerimaan sebesar Rp838.215,69.

\section{c. Pendapatan Usahatani Sawi}

Total pendapatan petani sayur sawi di KEM desa Bannae diperoleh dengan menghitung selisih antara total penerimaan dengan total biaya sehingga diperoleh total pendapatan usahatani sawi sebesar Rp7.178.000,00 dengan ratarata pendapatan usahatani sawi sebesar Rp140.745,10 per musim tanam. Ratarata biaya produksi, penerimaan dan pendapatan dapat dilihat pada Gambar 2 . Pendapatan setiap petani dari usahatani sawi di KEM desa Bannae ini masih lebih rendah dari pendapatan setiap petani di desa Humusu Oekolo. Menurut Nubatonis, (2016) rata-rata pendapatan petani di desa Humusu Oekolo dari usahatani sawi sebesar Rp250.000,00.

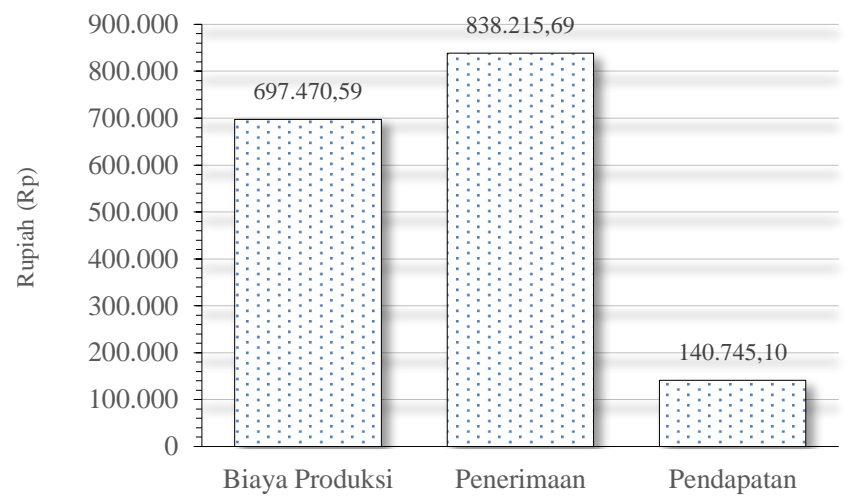

Gambar 2. Rata-rata Pendapatan Usahatani Sawi di KEM desa Bannae

\section{Simpulan}

Usahatani sawi di desa Bannae dimulai dari pengolahan lahan dilakukan oleh tenaga kerja pria dan wanita, tanah diolah menggunakan alat-alat meliputi pacul, linggis, parang, dan tajak, kemudian dilanjutkan dengan persiapan benih. Penanaman dilakukan setelah bibit sayur sawi mempunyai 4 sampai 5 helai daun. Sebelum penanaman bedengan disiram terlebih dahulu. Petani membuat lubang tanam pada bedengan jarak $+20 \times 20 \mathrm{~cm}$. Bibit sayur sawi ditanam 2-3 bibit per lubang. Setelah tanam bedengan disiram dengan air secukupnya. Selanjutnya dilakukan pemeliharaan hingga panen dan pasca panen. Rata-rata biaya yang dikeluarkan petani dalam berusahatani sawi sebesar Rp697.470,59 dari total keseluruhan biaya yang dikeluarkan sebesar Rp35.571.000,00. Total penerimaan sebesar Rp42.749.000,00 dengan rata-rata sebesar Rp838.215,69. Total pendapatan petani sayur sawi sebesar Rp7.178.000,00 dengan rata-rata pendapatan sebesar Rp140.745,10 per musim tanam. 


\section{Pustaka}

Ating, S. \& Sambas, A.M. 2006. Aplikasi Statistika Dalam Penelitian. Bandung: Penerbit Pustaka Setia.

Hadisapoetro, S. 1973. Pembangunan Pertanian. Yogyakarta: Departemen Ekonomi Pertanian Fakultas Pertanian, Universitas Gadjah Mada.

Haryanto, E. 2007. Sawi \& Selada. Revisi ed. Seri Agribisnis. Jakarta: Penebar Swadaya.

Nubatonis, A. 2016. Analisis Pendapatan Usahatani Sawi di Desa Humusu Oekolo Kecamatan Insana Utara Kabupaten Timor Tengah Utara. AGRIMOR, 1(01): 1-2.

Pay, Y.A. \& Nubatonis, A. 2017. Analisis Pemasaran Buncis di Desa Oerinbesi Kecamatan Biboki Tanpah Kabupaten Timor Tengah Utara. AGRIMOR, 2(04): 52-54.

Redaksi Health Secret, 2015. Salad Organik untuk Detoksifikasi Tubuh. Jakarta: Elex Media Komputindo.

Soekartawi 1995. Analisis Usaha Tani. Jakarta: Universitas Indonesia Press.

Sugiyono, 2006. Metode Penelitian Kuantitatif, Kualitatif dan $R \&$ D. Bandung: Alfabeta.

Sunarjono, H. 2002. Bertanam 30 Jenis Tanaman Sayur. Seri Agribisnis. Jakarta: Penebar Swadaya.

Suratiyah, K. 2006. Ilmu Usahatani. Revisi ed. Jakarta: Penebar Swadaya.

Taena, W. 2009. Kajian Pengembangan Ekonomi Wilayah Perbatasan Kabupaten Timor Tengah Utara dengan District Enclave Oekusi. [Tesis] Institut Pertanian Bogor.

Usboko, A.M. \& Fallo, Y.M. 2016. Faktor Sosial Ekonomi yang Mempengaruhi Produksi Usahatani Sayuran Sawi di Kelompok Tani Mitra Timor AGRIMOR, 1(03): 60-62. 